\title{
Modeling Minority Stress Effects on Homelessness and Health Disparities among Young Men Who Have Sex with Men
}

\author{
Douglas Bruce, Ron Stall, Aimee Fata, and Richard T. Campbell
}

\begin{abstract}
Sexual minority youth are more likely to experience homelessness, and homeless sexual minority youth report greater risk for mental health and substance abuse symptoms than homeless heterosexual youth, yet few studies have assessed determinants that help explain the disparities. Minority stress theory proposes that physical and mental health disparities among sexual minority populations may be explained by the stress produced by living in heterosexist social environments characterized by stigma and discrimination directed toward sexual minority persons. We used data from a sample of 200 young men who have sex with men (YMSM) (38\% African American, $26.5 \%$ Latino/Hispanic, $23.5 \%$ White, $12 \%$ multiracial/other) to develop an exploratory path model measuring the effects of experience and internalization of sexual orientation stigma on depression and substance use via being kicked out of home due to sexual orientation and current homelessness. Direct significant paths were found from experience of sexual orientation-related stigma to internalization of sexual orientation-related stigma, having been kicked out of one's home, experiencing homelessness during the past year, and major depressive symptoms during the past week. Having been kicked out of one's home had a direct significant effect on experiencing homelessness during the past 12 months and on daily marijuana use. Internalization of sexual orientation-related stigma and experiencing homelessness during the past 12 months partially mediated the direct effect of experience of sexual orientation-related stigma on major depressive symptoms. Our empirical testing of the effects of minority stress on health of YMSM advances minority stress theory as a framework for investigating health disparities among this population.
\end{abstract}

KEYWORDS Minority stress, Marijuana, Homeless, YMSM, Sexual minority youth

Emerging adults in the USA report the highest rates of depression, heavy alcohol use, and daily marijuana use compared to other age groups. ${ }^{1,2}$ The escalation of these behavioral health issues has been attributed to the developmentally distinctive features of emerging adulthood, such as identity exploration, instability, focus on the self, feeling "in between" adolescence and adulthood, and possibilities. ${ }^{3}$ This transitional period between adolescence and adulthood may be reshaped by experiencing homelessness or being kicked out of one's parental home. ${ }^{4}$ Developmental tasks that typically characterize emerging adulthood, such as independent

Bruce and Fata are with the Department of Health Sciences, DePaul University, Chicago, IL, USA; Stall is with the Department of Behavioral and Community Health Sciences, Graduate School of Public Health, University of Pittsburgh Schools of the Health Sciences, Pittsburgh, PA, USA; Campbell is with the Institute for Health Research and Policy, University of Illinois at Chicago, Chicago, IL, USA.

Correspondence: Douglas Bruce, Department of Health Sciences, DePaul University, Chicago, IL, USA. (E-mail: dbruce1@depaul.edu) 
decision making, financial independence, and establishing a household, ${ }^{5,6}$ may come with significant adversity for youth who have been kicked out and had to assert independence relatively early compared to stably housed peers. ${ }^{4}$

Population-based studies have shown that homeless and marginally housed youth report exhibit significant behavioral health disparities compared to stably housed youth, including depression ${ }^{7,8}$ and substance use. ${ }^{7,9}$ Much of the disparities exhibited by youth experiencing homelessness have been attributed to past early and background negative life experiences. ${ }^{10-13}$ Numerous studies using community-based samples of homeless youth have documented that sexual minority youth are more likely to experience homelessness, and homeless sexual minority youth report greater risk for mental health and substance abuse symptoms than homeless heterosexual youth, ${ }^{14-19}$ yet few among these have assessed determinants that help explain the disparities between sexual minority youth and heterosexual youth experiencing homelessness.

Minority stress theory proposes that physical and mental health disparities among sexual minority populations may be explained by the stress produced by living in heterosexist social environments characterized by stigma and discrimination directed toward sexual minority persons. ${ }^{20,21}$ Dimensions of minority stress, including experiencing and internalizing stigma due to sexual orientation, have been shown to have significant associations with negative health outcomes among adult gay and bisexual men, ${ }^{21-24}$ sexual minority youth, ${ }^{25}$ and in particular among young males who have sex with men (YMSM) ${ }^{26-28}$ High rates of depression, substance use, and HIV/AIDS among groups of adult gay men have also been theorized to arise from negative childhood or adolescent experiences associated with their emergent samesex identities in heterosexist environments. ${ }^{29}$

In general, sexual minority adolescents report negative health disparities compared to heterosexual adolescents due to increased risk of experiencing minority stress-related stressors, including bullying, verbal abuse, violence, and social marginalization. ${ }^{30}$ Such experiences of discrimination have been documented to be associated with dropping out of school, running away, and being kicked out of parental homes, ${ }^{14,17,31,32}$ resulting in developmental trajectories that place such sexual minority young persons at increased risk. Family rejection has been reported to be significantly associated with negative health outcomes for white and Latino gay and lesbian adolescents, including depressive symptoms, drug use, sexual risk behavior, and suicide attempts. ${ }^{32}$ Reviews of prior research have documented links between verbal and physical harassment from family and peers, running away and experience homelessness, and elevated substance use and depression among sexual minority youth who have experiencing homelessness. ${ }^{16,33,34}$ Findings from a representative sample of high school students point to rejection and discrimination within the family due to sexual orientation as a likely cause of homeless disparities experienced by sexual minority youth compared to heterosexual youth, but little research has assessed possible causal factors of these disparities. ${ }^{15}$ Although experiencing homelessness as an outcome of discrimination and marginalization has been documented among samples of sexual minority youth, research that that empirically examines the effects of minority stress on developmental pathways associated with homelessness and health of YMSM has been limited.

Although there is substantial research comparing health outcomes of sexual minority homeless adolescents in relation to their heterosexual homeless adolescents, health disparities sexual minority homeless youth exhibit have seldom been analyzed in comparison to their sexual minority peers who have not experienced homelessness. How minority stress varies among sexual minority youth and how it may help 
explain associations between health outcomes and homelessness among sexual minority youth is not well understood. A small number studies have analyzed the health of homeless sexual minority youth compared to stably housed sexual minority youth, ${ }^{10,35,36}$ and each have provided insights into the relationships to background experiences, stressors, homelessness, and health that differentiate risks among sexual minority youth. Each of these studies has assessed stressors experienced among sexual minority youth experiencing homelessness, although types and timing of stressors have differed across studies.

In order to investigate how the development of depressive, anxiety, substance abuse symptoms, and conduct problems among sexual minority youth was associated with experiencing homelessness, Rosario, et al. compared health indicators over 12 months among homeless and non-homeless sexual minority youth, with social support and stressful events modeled as mediating factors. ${ }^{35}$ In this study, stressful events over the course of data collection included discriminatory events attributed to sexual orientation, and the investigators controlled for early childhood stressors such as sexual abuse and early development of sexual orientation. Although earlier childhood stressors were marginally higher in the homeless subsample at baseline, the psychological symptoms that developed in the cohort were significantly associated with stressful events associated with homelessness. Additional analyses indicated that homelessness was significantly associated with early sexual development, and childhood sexual abuse, and onset of substance use among homeless youth was concurrent or subsequent to first experiencing homelessness. $^{36}$

Clatts et al. examined past stressful experiences in a sample composed of YMSM who were currently homeless, had experienced homelessness but were currently stably housed, and who had never experienced homelessness. ${ }^{10}$ All three groups reported high levels of background stressful events, foster care, or involvement in criminal justice systems. Although the majority of homeless and non-homeless youth reported background negative life experiences, and lifetime substance use was pronounced in all three groups, examination of the timing of events across the groups revealed that negative life events occurred prior to the onset of substance use. The results suggest that elevated drug use among homeless YMSM may be largely indicative of adaptive adjustment to homelessness rather than consistent with preexisting behavioral patterns prior to homelessness.

Little research has been conducted with YMSM that models paths between minority stress dimensions, homelessness, and health behavior variables such as mental health and substance use. In order to better understand how variance in minority stress among YMSM may help explain disparities in homelessness and health behavior among this population, we empirically explored developmental trajectories that led from minority stress to experiences of homelessness and negative health outcomes. We used data from a sample of YMSM to develop a path model that measured the effects of experience and internalization of sexual orientation stigma on depression and substance use via being kicked out of home due to sexual orientation and current homelessness.

\section{HYPOTHESES}

We hypothesized that YMSM who reported higher levels of minority stress would be more likely to report being kicked out and experience recent homelessness and that 
YMSM who experienced homelessness would be more likely to report elevated levels of substance use and depressed mood.

\section{METHODS}

\section{Study Procedures}

The sample consisted of 200 YMSM ages 16-24 who participated in the Chicago Young Men's Health Study, a study investigating associations among identity development, social marginalization, and health behaviors among YMSM. Participants were recruited using multiple recruitment methods, including online advertisements (on Facebook), flyers and handcards distributed at community venues, and peer referral, during 2012. Eligibility criteria limited participants to the ages 16-24, being born a biological male, and having oral or anal sex with another male during the past 12 months.

Written informed consent was obtained from all participants 18 years and older; for participants younger than 18, we obtained written informed assent. Documentation of parental consent for participants younger than 18 was waived in order to avoid the selection biases present in recruiting only youth whose parents are both aware of and comfortable with their sexual orientation. Participants were surveyed using audio computer-assisted survey interview format (ACASI) in English on a range of minority stress, demographic, and health behavior variables. The survey took approximately $1 \mathrm{~h}$ to complete, and each participant was paid $\$ 40$ for his time. Upon completion of the survey, as part of the peer referral recruitment method, each participant was asked if they were interested in letting a friend who met the study criteria know about the study, and if the participant agreed, they were given a handcard to pass on to such a friend. The research protocol was approved by the institutional review board at DePaul University.

\section{Measures}

Demographic Variables and Indicators of Homelessness Various demographic variables of interest were collected, including age, race/ethnicity, sexual orientation, education, and employment. In addition, we assessed homelessness utilizing three dichotomous (yes/no) measures: ever being kicked out of one's home due to sexual orientation, ever homeless during one's lifetime, and ever homeless during the past 12 months.

Minority Stress Variables Experience of sexual orientation stigma was measured using the summed score of an eight-item scale adapted from previously validated measures. ${ }^{23,24}$ Responses used four categories assessing frequency $(1=$ never, $4=$ many times). Examples of items on the scale include, "While growing up, how often were you made fun of or called names (faggot, queer, sissy, etc.) by your own family, because of the way you behaved?" and "How often has a friend rejected you because of your sexual orientation?" and "How often has your family ignored or refused to acknowledge your sexual orientation?" Internal consistency of the scale was assessed using Cronbach's alpha $(\alpha=0.93)$.

Internalization of sexual orientation stigma was measured using the summed score of a nine-item scale adapted from previously validated measure. ${ }^{23,24,37}$ Responses used four categories assessing agreement (1=strongly disagree, $4=$ 
strongly agree). Examples of items on the scale include, "I have tried to stop being attracted to men" and "If there were a pill to make me straight I would take it" and "Sometimes I feel ashamed of my sexual orientation." Internal consistency of the scale was assessed using Cronbach's alpha $(\alpha=0.87)$.

Depressive Symptoms Depressive symptomology was measured using the Center for Epidemiologic Studies (CESD) depression scale, a 20-item measure that has been used widely to assess depressive symptomology in ethnically diverse groups of adolescents. ${ }^{38-40}$ We used the conventional cutoff to measure major depressive symptoms (summative scores higher than 21 out of possible 60 ).

Substance Use The frequency of alcohol and marijuana use was assessed during the past 3 months (did not use/has never used, less than weekly, more than weekly but less than daily, daily). Cocaine, methamphetamine, and ecstasy use were assessed by any use of during the past 3 months. For the purposes of path analysis, we dichotomized the alcohol and marijuana use variables into "daily use" and "less than daily use/no use" and transformed the cocaine, methamphetamine, and ecstasy variables into "any hard drug use."

\section{Data Analysis}

We utilized MPlus software to test exploratory path models that best predicted paths from minority stress dimensions to dichotomous indicators of homelessness, major depression, and substance use. Indicators of homelessness were modeled as endogenous, observed variables and regressed on latent, exogenous minority stress dimensions. Major depression, daily marijuana use, daily alcohol use, and any hard drug use were modeled as endogenous, observed variables. Direct paths were specified between the minority stress dimensions and the indicators of homelessness, mental health, and substance use variables. Indirect paths were specified from the minority stress dimensions through the indicators of homelessness to the mental health and substance use variables. Race/ethnicity was modeled as an exogenous variable, and minority stress dimensions were regressed on dichotomous variables for Black/African American, Latino/Hispanic, and White/Caucasian. Robust maximum likelihood methods (MLR) were utilized to define a final model through iterative testing of paths and assessment of fit indices using Akaike's information criterion (AIC) and Schwarz's Bayesian information criterion (BIC).

\section{RESULTS}

\section{Participant Characteristics}

Participant characteristics of the sample are presented in Table 1. Over one-third of the sample identified as Black or African American (38\%), with Latino/Hispanic and White/Caucasian participants, each constituting approximately one-quarter of the sample (26.5 and $23.5 \%$, respectively). Roughly two-thirds of participants identified as gay $(64.5 \%)$ and $28 \%$ identified as bisexual. In terms of homelessness, $27.5 \%$ reported being kicked out of their childhood home due to their sexual orientation, $46.5 \%$ reported ever being homeless during their lifetime, and $39.5 \%$ reported being homeless at least one night during the past 12 months. The mean age of the sample was 20.9 years. 
TABLE 1 Participant characteristics, behavioral health, minority stress measures

\begin{tabular}{|c|c|c|}
\hline & Number & Percent \\
\hline \multicolumn{3}{|l|}{ Race/ethnicity } \\
\hline Black/African American & 76 & 38.0 \\
\hline Latino/Hispanic & 53 & 26.5 \\
\hline White/Caucasian & 47 & 23.5 \\
\hline Asian American & 4 & 2.0 \\
\hline Native American/Alaskan Native & 2 & 1.0 \\
\hline Multiracial/other & 18 & 9.0 \\
\hline \multicolumn{3}{|l|}{ Sexual orientation } \\
\hline Gay & 129 & 64.5 \\
\hline Bisexual & 57 & 28.5 \\
\hline Other & 14 & 7.0 \\
\hline \multicolumn{3}{|l|}{ Ever kicked out of parents' home due to sexual orientation } \\
\hline Yes & 55 & 27.5 \\
\hline \multicolumn{3}{|l|}{ Ever homeless during lifetime } \\
\hline Yes & 93 & 46.5 \\
\hline \multicolumn{3}{|l|}{ Ever homeless during past 12 months } \\
\hline Yes & 79 & 39.5 \\
\hline \multicolumn{3}{|l|}{ Depressive symptoms, past 7 days } \\
\hline Asymptomatic (CESD $\leq 15)$ & 105 & 52.5 \\
\hline Minor $(15<$ CESD $<21)$ & 31 & 15.5 \\
\hline Major (CESD $\geq 21)$ & 64 & 32.0 \\
\hline \multicolumn{3}{|l|}{ Marijuana use, past 3 months } \\
\hline Did not use/has never used & 97 & 48.5 \\
\hline Less than weekly & 44 & 22.0 \\
\hline Weekly, less than daily & 26 & 13.0 \\
\hline Daily & 33 & 16.5 \\
\hline \multicolumn{3}{|l|}{ Alcohol use, past 3 months } \\
\hline Did not use/has never used & 43 & 21.5 \\
\hline Less than weekly & 91 & 45.5 \\
\hline Weekly, less than daily & 59 & 29.5 \\
\hline Daily & 7 & 3.5 \\
\hline \multicolumn{3}{|l|}{ Any cocaine, ecstasy, or methamphetamine use, past 3 months } \\
\hline \multirow[t]{2}{*}{ Yes } & 15 & 7.5 \\
\hline & M & SD \\
\hline Age & 20.88 & 2.09 \\
\hline Experience of sexual orientation-related stigma (8 items, 4 -pt scale, $\alpha=0.93$ ) & 1.15 & 0.83 \\
\hline $\begin{array}{l}\text { Internalization of sexual orientation-related stigma (9 items, 4-pt scale, } \\
\qquad \alpha=0.87 \text { ) }\end{array}$ & 1.94 & 0.78 \\
\hline
\end{tabular}

\section{Minority Stress}

Psychometrics for experience and internalization of stigma scales for the total sample are summarized in Table 1. Comparison of means among racial/ethnic subgroups showed that Latino participants reported significantly higher frequency of experience of stigma due to sexual orientation $(M=1.327, p<0.05)$ than White participants $(M=0.856)$. African American participants' reported experience $(M=$ 1.227) was not significantly different from either Whites or Latinos. African Americans reported significantly higher levels of internalization of stigma due to sexual orientation $(M=2.197, p<0.001)$ compared to both Latinos $(M=1.696)$ and Whites $(M=1.659)$. 


\section{Mental Health and Substance Use}

Measures of mental health and substance use are summarized in Table 1. Almost one-third $(32 \%)$ of participants reported major depression symptomology (CESD $\geq 21$ ) during the past week, and $16.5 \%$ reported daily marijuana use during the past 90 days. Only $3.5 \%$ of the sample reported daily alcohol use, and $7.5 \%$ reported any cocaine, ecstasy, or methamphetamine use during the past 3 months.

\section{Path Analysis}

We tested iterations of the model to include all significant paths, while optimizing fit indices (AIC, BIC). Preliminary models failed to produce any significant paths to daily alcohol use and any hard drug use from the minority stress or homelessness variables. Despite the significant differences in mean minority stress among racial/ ethnic groups in the ANOVA described above, none of the three racial/ethnic groups entered into the model produced significant paths to experience and internalization of stigma due to sexual orientation. Successive models were tested until all paths between variables approached statistical significance. Figure 1 depicts the final model with significant paths, and Table 2 shows the estimated coefficients and odds ratios associated with the paths in the final model. We retained the path from pastyear homelessness to past-week major depression due to its marginal significance. Our final path model demonstrated adequate fit using MLR for logistic outcomes (final model: $\mathrm{AIC}=1229.670, \mathrm{BIC}=1275.635$ ), as well as when tested using conventional maximum likelihood $(\mathrm{ML})$ for linear models $(\mathrm{RMSEA}=0.051$ and $\mathrm{CFI}=0.991)$.

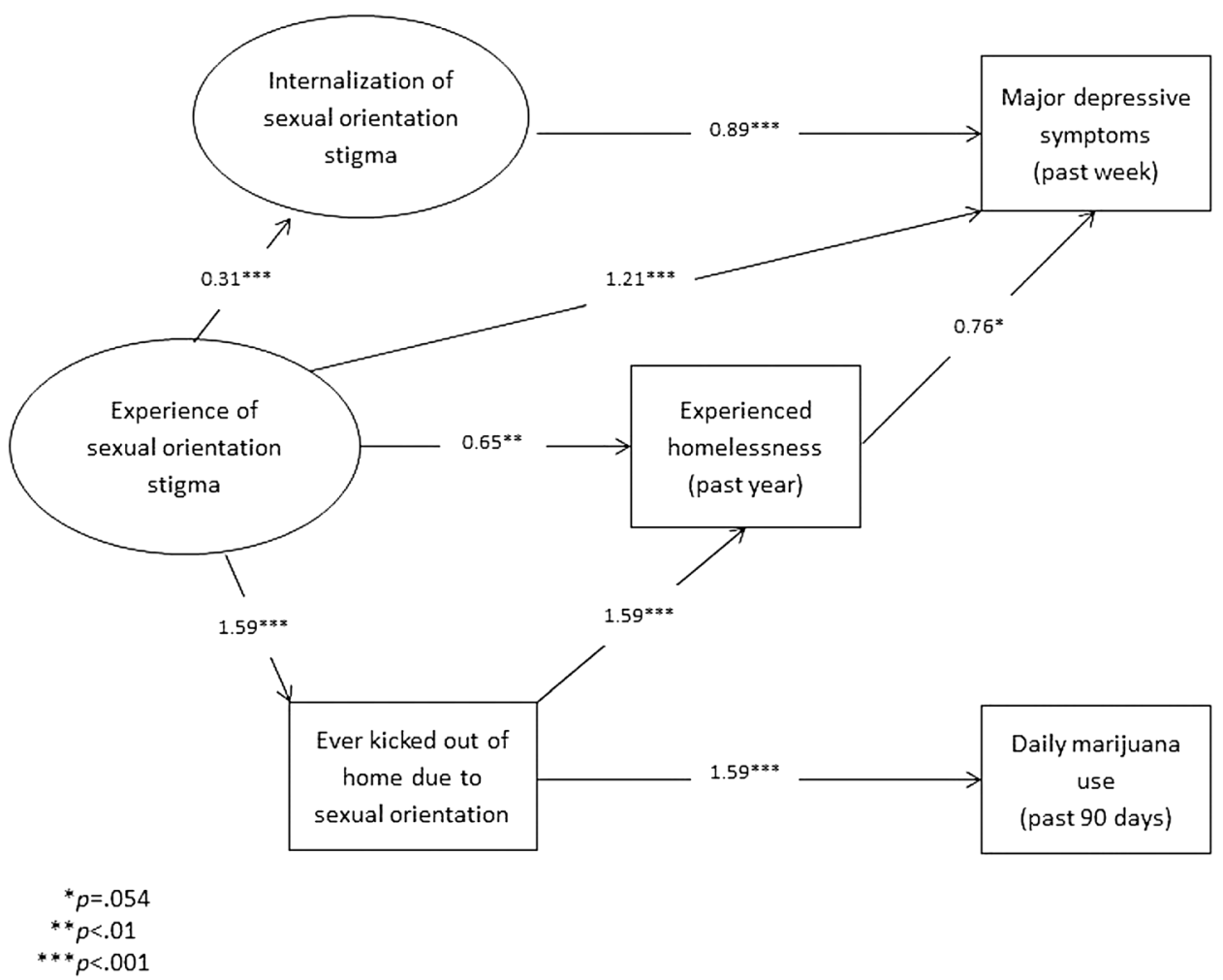

FIGURE 1. Final path model and estimates. 
TABLE 2 Path estimates and odds ratios

\begin{tabular}{|c|c|c|c|c|c|}
\hline & $\beta$ & S.E. & O.R. & C.I. of O.R. & $p$ \\
\hline \multicolumn{6}{|l|}{ Ever kicked out of parents' home } \\
\hline Experience of sexual orientation stigma & 1.59 & 0.26 & 4.90 & $(3.21,7.48)$ & 0.000 \\
\hline \multicolumn{6}{|l|}{ Experienced homelessness (past 12 months) } \\
\hline Experience of sexual orientation stigma & 0.65 & 0.24 & 1.91 & $(1.29,2.84)$ & 0.007 \\
\hline Ever kick out of parents' home & 1.59 & 0.45 & 4.90 & $(2.35,10.21)$ & 0.000 \\
\hline \multicolumn{6}{|l|}{ Smoked marijuana daily (past 3 months) } \\
\hline Ever kicked out of parents' home & 1.59 & 0.38 & 4.90 & $(2.61,9.17)$ & 0.000 \\
\hline \multicolumn{6}{|l|}{ Major depressive symptoms (past week) } \\
\hline Experience of sexual orientation stigma & 1.21 & 0.23 & 3.36 & $(2.29,4.94)$ & 0.000 \\
\hline Internalization of sexual orientation stigma & 0.89 & 0.25 & 2.44 & $(1.63,3.66)$ & 0.000 \\
\hline Experienced homelessness (past 12 months) & 0.76 & 0.39 & 2.13 & $(1.12,4.06)$ & 0.054 \\
\hline
\end{tabular}

Direct significant paths were found from experience of sexual orientation-related stigma to internalization of sexual orientation-related stigma $(\beta=0.31, p>0.001)$, having been kicked out of one's home $(\beta=1.59$, O.R. $=4.90, p>0.001)$, experiencing homelessness during the past year $(\beta=0.65$, O.R. $=1.91, p>0.01)$, and major depressive symptoms during the past week $(\beta=1.21, \mathrm{O} . \mathrm{R} .=3.36, p>0.001)$. Both internalization of sexual orientation-related stigma and experiencing homelessness during the past 12 months partially mediated the direct effect of experience of sexual orientation-related stigma on major depressive symptoms. Having been kicked out of one's home had a direct significant effect on experiencing homelessness during the past 12 months $(\beta=1.59$, O.R. $=4.90, p>0.001)$ and daily marijuana use $(\beta=1.59$, O.R. $=4.90, p>0.001)$.

\section{DISCUSSION}

Our study explored developmental paths associated with experiencing and internalizing sexual orientation stigma, being kicked out of one's home due to sexual orientation, recent homelessness, and current depression and substance use. The final path model fit the data well and points to negative health outcome trajectories among YMSM associated experiencing sexual orientation stigma and being kicked out of one's home, with multiple paths to major depressive symptoms and a distinct path to daily marijuana use. Experiencing sexual orientation-related stigma had a direct significant effect on major depressive symptoms and indirect effects partially mediated by internalized homophobia and being homeless in the past 12 months (which demonstrated a marginally significant association with major depression). Experiencing sexual orientation-related stigma had an indirect effect on daily marijuana use mediated by having been kicked out of one's home. The results suggest that there are differentiated effects of ever being kicked out of one's childhood home and experiencing current homelessness, with being kicked out increasingly the likelihood of daily marijuana use and past-year homelessness fivefold, and past-year homelessness marginally mediating the effects of experiencing sexual orientation stigma on past-week major depression.

One explanation for the distinct trajectories may be that elevated marijuana use may serve as an adaptive coping mechanism over time for emotional trauma experienced from being kicked out of one's parental home. Previous research has 
documented elevated substance use as a coping response to past negative life events and street-survival among both marginally housed YMSM, ${ }^{10}$ although our results suggest that ever being kicked out of one's home is a significantly larger predictor of daily marijuana use than past-year homelessness. Substance use among YMSM has also been shown to be associated with experiencing dimensions of minority stress, ${ }^{27,28}$ and being kicked out of one's home has been associated with a range of negative health outcomes among sexual minority youth. ${ }^{32}$ Significantly, depression was not directly linked to being kicked out of one's home in our sample, as has been reported in other studies. ${ }^{32}$ We found no direct effect of experiencing sexual orientation stigma on daily marijuana use, nor was daily marijuana use associated with major depression, internalization of sexual orientation stigma, or homelessness during the past year. Our results point to the need for more research on the role that daily marijuana use serves among groups of YMSM, particularly those who have been kicked out of their parental homes.

Major depression, conversely, was significantly associated with internalized homophobia and marginally associated with any past-year homelessness $(\mathrm{OR}=$ 2.13, $p=0.054)$. Being kicked out of one's home did not have direct effects on current major depression, although those who were currently homeless were twice as likely to report major depression and five times more likely to have been kicked out of home. Current or more recent homelessness appears to increase the likelihood for current depression than does a history of being kicked out of one's home, although this relationship is not nearly as strong as the association between being kicked out and current daily marijuana use. Internalization of sexual orientation stigma increased by 2.5 times the likelihood of major depression, although this association was smaller than the effect that of experiencing sexual orientation stigma. The interconnection between internalization of sexual orientation stigma, homelessness, and depression is consistent with that reported previously in research with YMSM. ${ }^{41}$

Previous research has debated whether prior drug use among youth may predict homelessness or does homelessness serve as a predictor of drug use, and determining which is an antecedent to the other has been difficult to ascertain due to the crosssectional methods used in most of the studies of homeless youth. ${ }^{10,42,43}$ Our results suggest that experiencing stigma relating to one's sexual orientation and ever being kicked out of one's home increase the risk of elevated marijuana use tremendously within groups of YMSM, regardless of their current housing status. Despite our cross-sectional design, there are sequential paths implicit in the model due to the temporal frames embedded in the measures: experience of sexual orientation-related stigma in the past, ever being kicked out of one's home, experiencing homelessness over the past 12 months, daily marijuana use during the past 90 days, and major depressive symptoms over the past 7 days.

The experience and internalization of sexual orientation stigma may help explain continuing health disparities experienced by YMSM. Ever being kicked out of home due to sexual orientation would appear to substantially mediate the effects of experiencing sexual orientation stigma in YMSM during their adolescence and emerging adulthood. This pathway may help predict experiences of homelessness among YMSM, as well as behavioral health disparities between YMSM experiencing homelessness and stably housed YMSM. High rates of major depression and daily marijuana use in our sample greatly exceeded those reported in the emerging adult population in the USA. ${ }^{1,44}$ The high rate of homelessness in our sample, while it may be due to our peer-based sampling methods, allowed us to make meaningful 
comparisons regarding minority stress, homelessness, major depressive symptoms, and elevated marijuana use among homeless and stably housed YMSM. This analysis may help inform future population-based studies to identify sources of health disparities within groups of YMSM.

Our findings are subject to several limitations present within the study. First, assumptions of causality regarding the paths in our final model cannot be inferred due to the cross-sectional design of the study. Although the minority stress/stigma variables and incidence of being kicked out of home cover lifetime experiences and the homeless indicator, substance use, and mental health variables were temporally ordered (e.g., past 12 and 3 months and past week, respectively), all the data were collected at the same time and hence subject to, at least, recollection bias. In addition, there are several potential variables missing in our study that could further help delineate paths in our final model. For instance, we did not assess childhood sexual abuse, involvement in foster care or juvenile justice systems, social support or social network variables, or resilience measures, all of which have been shown to have associations with our behavioral health outcomes of interest among homeless youth. ${ }^{13,42,45,46}$ Generalization of our findings are limited by the non-probabilitybased sampling methods employed in the study, although the overrepresentation of YMSM who had been kicked out of their homes and/or experience recent homelessness allowed us to make meaningful interpretations between those youth and the stably housed YMSM in the sample. Lastly, we relied solely on self-reported data, but we believe that the use of an ACASI to gather data may have lessened the inclination of participants to underreport levels of substance use and depressive symptoms.

There are multiple opportunities for interventions to mitigate how YMSM experience, stigma, discrimination, and marginalization and to promote their healthy development. Family-based interventions are needed to help families adapt to adolescent emergent sexual orientation identities and help prevent negative health outcomes. Measures have been developed to assess family acceptance of sexual orientation of sexual minority youth, and acceptance has been shown to be protective for depression, substance use, and suicidal ideation, despite differences in levels of acceptance due to ethnicity, immigration status, and religious affiliation. ${ }^{47}$ School-based intervention, including trainings to develop more supportive staff and teachers, as well as peer-based programming, are warranted given the high incidence of discrimination sexual minority youth attributed to peers in schools during their adolescence, and policy recommendations for safer school environments for sexual minority youth have been developed. ${ }^{48}$ The development of social networking sites that promote the healthy identity development of gay and bisexual youth is an opportunity to reach this population while they may be experiencing isolation and marginalization within their home communities and exploring their emergent sexual orientation identities via online communities. ${ }^{49,50}$

Our empirical testing of the effects of minority stress on health of YMSM advances minority stress theory as a framework for investigating health disparities among this population. Results from our path analysis suggest that there are differentiated effects of ever being kicked out of one's childhood home and experiencing current homelessness. This study points toward the need for more research on the role that daily marijuana use serves among groups of YMSM. Further testing of our model among a population-based sample of YMSM, with additional variables such as childhood sexual abuse, involvement in criminal justice 
and foster care systems, as well as coping measures, may help more precisely estimate effects that are suggested in our exploratory model.

\section{ACKNOWLEDGMENTS}

Support for this study was provided by funding from the National Institute of Mental Health under grant K01 MH 089838. Our deep gratitude goes to our research participants whose thoughtful input made this study possible.

\section{REFERENCES}

1. Johnston LD, O'Malley PM, Bachman JG, Schulenberg JE. Monitoring the Future National Survey Results on Drug Use, 1975-2009. Volume I: Secondary School Students. (NIH Publication No. 10-7584). Bethesda, MD: National Institute on Drug Abuse; 2010.

2. Park MJ, Mulye TP, Adams SH, Brindis CD, Irwin CE. The health status of young adults in the United States. J Adolesc Health. 2006; 39: 305-317.

3. Arnett JJ. The developmental context of substance use in emerging adulthood. J Drug Issues. 2005; 35(2): 235-253.

4. Whitbeck LB. Mental Health and Emerging Adulthood among Homeless Young People. New York, NY: Psychology; 2009.

5. Arnett JJ. Emerging adulthood: a theory of development from the late teens through the twenties. Am Psychol. 2000; 55: 469-480.

6. Arnett JJ. Emerging Adulthood. New York, NY: Oxford U. Press; 2004.

7. Thompson SJ, Maguin E, Pollio DE. National and regional differences among runaway youth using federally-funded crisis services. J Soc Serv Res. 2003; 30(1): 1-17.

8. Tyler KA, Hagewan KJ, Melander LA. Risk factors for running away among a general population sample of males and females. Youth Soc. 2011; 43: 583-608.

9. Greene JM, Ennett ST, Ringwalt CL. Substance use among runaway and homeless youth in three national samples. Am J Public Health. 1997; 87(2): 229-235.

10. Clatts MC, Goldsamt L, Yi H, Gwadz MV. Homelessness and drug abuse among young men who have sex with men in New York City: a preliminary epidemiological trajectory. J Adolesc. 2005; 28(2): 201-214.

11. Molnar BE, Shade SB, Kral AH, Booth RE, Watters JK. Suicidal behavior and sexual/ physical abuse among street youth. Child Abuse Negl. 1998; 22: 213-222.

12. Rotheram-Borus MJ, Mahler KA, Koopman C, Langabeer K. Sexual abuse history and associated multiple risk behavior in adolescent runaways. Am J Orthopsychiatry. 1996; 66(3): 390-400.

13. Whitbeck LB, Hoyt DR. Nowhere to grow: homeless and runaway adolescents and their families. New York, NY: Aldine de Gruyter; 2009.

14. Cochran BN, Stewart AJ, Ginzler JA, Cauce AM. Challenges faced by homeless sexual minorities. Comparison of LGBT homeless adolescents with their heterosexual counterparts. Am J Public Health. 2002; 92(5): 773-777.

15. Corliss HL, Goodenow CG, Nichols L, Austin SB. High burden of homelessness among sexual minority adolescents: findings from a representative Massachusetts High School sample. Am J Public Health. 2011; 101(9): 1683-1689.

16. Gattis MN. An ecological systems comparison between homeless sexual minority youths and homeless heterosexual youths. Soc Sci Res. 2013; 39(1): 38-49.

17. Whitbeck LB, Chen X, Hoyt DR, Tyler KA, Johnson KD. Mental disorder, subsistence strategies, and victimization among gay, lesbian, and bisexual homeless and runaway adolescents. J Sex Res. 2004; 41(4): 329-342. 
18. Noell JW, Ochs LM. Relationship of sexual orientation to substance use, suicidal ideation, suicide attempts, and other factors in a population of homeless adolescents. $J$ Adolesc Health. 2001; 29: 31-36.

19. Leeuwen JM, Boyle S, Salomonsen-Sautel S, et al. Lesbian, gay, and bisexual homeless youth: an eight-city public health perspective. Child Welfare. 2006; 85(2): 151-170.

20. Mays VM, Cochran SD. Mental health correlates of perceived discrimination among lesbian, gay, and bisexual adults in the United States. Am J Public Health. 2001; 91(11): 1869-1876.

21. Meyer IH. Prejudice, social stress, and mental health in lesbian, gay, and bisexual populations. Pscyhol Bull. 2003; 129(5): 674-697.

22. Meyer IH, Dean L. Internalized homophobia, intimacy, and sexual behavior among gay and bisexual men. In: Herek GM, ed. Stigma and Sexual Orientation. Thousand Oaks, CA: Sage; 1995: 160-186.

23. Diaz RM, Ayala G, Bein E, Henne J, Marin BV. The impact of homophobia, poverty, and racism on the mental health of gay and bisexual Latino men: findings from 3 U.S. cities. Am J Public Health. 2001; 91(6): 927-932.

24. Bruce D, Ramirez-Valles J, Campbell R. Stigmatization, substance use, and sexual risk behavior among Latino gay and bisexual men and transgender persons. J Drug Issues. 2008; 38(1): 235-260.

25. Almeida J, Johnson RM, Corliss HL, Molnar BE, Azrael D. Emotional distress among LGBT youth: the influence of perceived discrimination based on sexual orientation. $J$ Youth Adolesc. 2009; 38: 1001-1014.

26. Huebner DM, Rebchook GM, Kegeles SM. Experiences of harassment, discrimination, and physical violence among young gay and bisexual men. Am J Public Health. 2004; 94(7): 1200-1203.

27. Traube DE, Schrager SM, Holloway IW, Weiss G, Kipke MD. Environmental risk, social cognition, and drug use among young men who have sex with men: longitudinal effects of minority status on health processes and outcomes. Drug Alcohol Depend. 2013; 127(13): $1-7$.

28. Wong CF, Weiss G, Ayala G, Kipke M. Harassment, discrimination, violence and illicit drug use among young men who have sex with men. AIDS Educ Prev. 2010; 22(4): 286298.

29. Stall R, Friedman M, Catania JA. Interacting epidemics and gay men's health: a theory of syndemic production among urban gay men. In: Wolitski RJ, Stall R, Valdiserri RO, eds. Unequal Opportunity: Health Disparities Affecting Gay and Bisexual Men in the United States. New York: Oxford U. Press; 2008: 251-274.

30. Coker TR, Austin SB, Schuster MA. The health and health care of lesbian, gay, and bisexual adolescents. Annu Rev Public Health. 2010; 31: 457-477.

31. Rew L, Whittaker TA, Taylor-Seehaver MA, Smith LR. Sexual health risks and protective resources in gay, lesbian, bisexual and heterosexual homeless youths. J Spec Pediatr Nurs. 2005; 10(1): 11-19.

32. Ryan C, Huebner D, Diaz RM, Sanchez J. Family rejection as a predictor of negative health outcomes in white and Latino lesbian, gay, and bisexual young adults. Pediatrics. 2009; 123(1): 346-352.

33. Milburn NG, Ayala G, Rice E, Batterham P, Rotheram-Borus MJ. Discrimination and exiting homelessness among homeless adolescents. Cult Divers Ethn Minor Psychol. 2006; 12(4): 658-672.

34. Savin-Williams RC. Verbal and physical abuse as stressors in the lives of lesbian, gay male, and bisexual youths: associations with school problems, running away, substance abuse, prostitution, and suicide. J Consult Clin Psychol. 1994; 62(2): 261-269.

35. Rosario M, Schrimshaw EW, Hunter J. Homelessness among Lesbian, gay, and bisexual youth: implications for subsequent internalizing and externalizing symptoms. $J$ Youth Adolesc. 2012; 51: 544-560. 
36. Rosario M, Schrimshaw EW, Hunter J. Risk factors for homelessness among lesbian, gay, and bisexual youths: a developmental milestone approach. Child Youth Serv Rev. 2012; 34: 186-193.

37. Wagner G. Internalized homophobia scale. In: Davis CM, Yarber WL, Bauserman R, Schreer GE, Davis S, eds. Handbook of Sexuality-Related Measures. Thousand Oaks, CA: Sage; 1998: 371-372.

38. Perreira KM, Deeb-Sossa N, Harris KM, Bollen K. What are we measuring? An evaluation of the CES-D across race/ethnicity and immigrant generation. Soc Forces. 2005; 83(4): 1567-1601.

39. Prescott CA, McArdle JJ, Hishinuma ES, et al. Prediction of major depression and dysthymia from CES-D scores among ethnic minority adolescents. J Am Acad Child Adolesc Psychiatry. 1998; 37(5): 495-503.

40. Radloff LS. The use of the center for epidemiologic studies depression scale in adolescents and young adults. J Youth Adolesc. 1991; 20(2): 149-166.

41. Nyamathi A, Branson C, Idemundia F, et al. Correlates of depressed mood among young stimulant-using homeless gay and bisexual men. Issues Ment Health Nurs. 2012; 33: 641-649.

42. Zerger S, Strehlow AJ, Gundlapalli AV. Homeless young adults and behavioral health: an overview. Am Behav Sci. 2008; 51: 824-841.

43. Kipke MD, Weiss G, Wong CF. Residential status as a risk factor for drug use and HIV risk among young men who have sex with men. AIDS Behav. 2007; 11: S59-S69.

44. Schulenberg JE, Zarrett NR. Mental health during emerging adulthood: continuity and discontinuity in courses, causes, and functions. In: Arnett JJ, Tanner JL, eds. Emerging Adults in America: Coming of Age in the 21st Century. Washington, DC: American Psychological Association; 2006: 135-172.

45. Rew L, Taylor-Seehaver MA, Thomas NY, Yockey RD. Correlates of resilience in homeless adolescents. J Nurs Sch. 2001; 33(1): 33-40.

46. Gattis MN. Psychosocial problems associated with homelessness in sexual minority youth. J Hum Behav Soc Environ. 2009; 19: 1066-1094.

47. Ryan C, Russell ST, Huebner D, Diaz RM, Sanchez J. Family acceptance in adolescence and the health of LGBT young adults. J Child Adolesc Psychiatr Nurs. 2010; 23(4): 205213.

48. Russell ST, Kosciw J, Horn S, Saewyc E. Safe schools policy for LGBTQ students. Soc Policy Rep. 2010; 24(4): 1-24.

49. Harper GW, Bruce D, Serrano P, Jamil OB. The role of the internet in the sexual identity development of gay and bisexual male adolescents. In: Hammack PL, Cohler BJ, eds. The Story of Sexual Identity: Life Course and Sexual Identity Narrative Perspectives on Gay and Lesbian Identity. New York, NY: Oxford U; 2009: 297-326.

50. Pingel ES, Bauermeister JA, Johns MM, Eisenber A, Leslie-Santana M. A safe way to explore: reframing risk on the internet amidst young gay men's search for identity. $J$ Adolesc Res. 2013; 28(4): 453-478. 